\title{
An integrated microwave technique for releasing microfossils from an indurated bone bed
}

\author{
Luke M. Hauser \\ School of Earth and Environmental Siences, University of Portsmouth, Burnaby Road, Portsmouth PO1 3QL, UK \\ luke.hauser@port.ac.uk
}

\begin{abstract}
Bone beds have often been a focus for micropalaeontological study as the high concentration of fossil material allows vertebrate palaeontologists the returns normally experienced only by nannofossil workers and palynologists. It is not always straightforward to release the fossil material within bone beds and the extraction of microfossils from the upper Silurian Downton Bone Bed is particularly challenging. Outlined here is an integrated method for processing this bone bed using liquid paraffin and a microwave oven, and a comparison in terms of quality and quantity with material recovered using other techniques. This integrated method allows for the recovery of microvertebrates, such as thelodonts, and also internal moulds of ostracods, brachiopods and early plant material.
\end{abstract}

Keywords: Silurian; Downton Bone Bed; microfossils; extraction; Welsh Borderlands

Received 12 February 2015; accepted 26 May 2015

The standard method to recover phosphatic microfossils, in particular microvertebrates, is to use acetic acid $\left(\mathrm{CH}_{3} \mathrm{COOH}\right)$ (Jeppsson et al. 1999). This is certainly the case when recovering material from the two best known UK bone beds, the Westbury and Ludlow bone beds (Antia \& Whitaker 1978; Swift \& Martill 1999). However, some bone beds lack calcium carbonate cement and thus do not break down at all in acetic acid. One such bone bed is the Downton Bone Bed of the upper Silurian of the Welsh Borders. Described here is an integrated method for use on such indurated bone beds with no calcium carbonate content.

Located $1.5 \mathrm{~m}$ above the Ludlow Bone Bed at Weir Quarry, Downton, Shropshire, UK [SO 4560 7525], the Downton Bone Bed lies within the Platyschisma Shale Member of the Downton Castle Sandstone Formation. The Platyschisma Shale Member was long considered to be of Přídolí age, but Loydell \& Frýda (2011) presented numerous lines of biostratigraphical and chemostratigraphical evidence demonstrating that it is mid-Ludfordian (late Ludlow Epoch). Another key piece of evidence indicating a Ludlow age for the Downton Bone Bed is the presence of abundant denticles of the thelodont Paralogania ludlowiensis (Gross, 1967). All records of this taxon from Gotland and the Baltic States are from the Ludlow Series (Miller \& Märss 1999): none are from the Prrídolí. Independent dating is provided by chitinozoans, e.g. in the Ohesaare core of Saaremaa, Estonia the lower Kuressaare Formation contains Paralogania ludlowiensis within the Ludfordian Eisenackitina lagenomorpha Biozone (Nestor 2009).

Despite micropalaeontological and palynological studies of the Platyschisma Shale Member within the last 25 years (e.g. Richardson \& Rasul 1990; Miller 1995; Miller \& Märss 1999), and brief mention of fossils from the Downton Bone Bed (e.g. Märss \& Miller 2004), the sedimentology and fossil content of the Downton Bone Bed have not been studied in any detail (Eberth et al. 2007).

\section{Sedimentology}

Despite being part of the Platyschisma Shale Member (Bassett et al. 1982), the Downton Bone Bed is in fact an extremely well-indurated quartz arenite. Thin sections (Fig. 1) show the nonfossil component of the bed is almost completely quartz within a clay matrix. The grains are tightly packed, which is the reason why the Downton Bone Bed is such a challenge to break down. The denticle-rich bands are found in discrete horizons usually in close proximity to layers rich in plant material. They appear to have been deposited as a result of storm activity. On bedding surfaces the denticles within the bone bed can be seen to be abraded, often with parts of the crown or base missing (Fig. 2). This is important to bear in mind when assessing the damage to specimens resulting from the different extraction methods.

\section{Methods}

\section{Other techniques assessed}

In trying to disaggregate the Downton Bone Bed a number of alternative techniques were tried before the method described herein was used. The first was the mechanical method described by Rixton (1976) and Green (2001, pp. 110-112). Although this did eventually yield material, the time it took (1 month) to break down the bed made it unsuitable to use. This problem was compounded by the poor quality of the fossils recovered; the denticle shown in Figure $3 \mathrm{a}$ is the best example from the residue recovered and it is clearly damaged, particularly on the base which has a sharp break. The presence of the clay matrix suggested that hydrogen peroxide $\left(\mathrm{H}_{2} \mathrm{O}_{2}\right)$ could be used. Although there was effervescence on the surface, the tight grain packing prevented the $\mathrm{H}_{2} \mathrm{O}_{2}$ from penetrating the rock. Freeze-thaw was also attempted using liquid nitrogen, boiling water and a microwave. This only caused the rock to split along bedding planes.

The Selfrag method is in its infancy in vertebrate palaeontology and has been used in metamorphic geology to extract accessory minerals (Giese et al. 2007). The method involves placing a sample, cut or split into small pieces, into a device upon which two electrical probes deliver high voltage pulses to the sample. This fragments the rock leaving the targeted grains intact. A $1 \mathrm{~kg}$ sample was processed using a probe gap of $20 \mathrm{~mm}$, a $5 \mathrm{~Hz}$ pulse frequency and a $90 \mathrm{kV}$ voltage. The sediment returned was sieved 


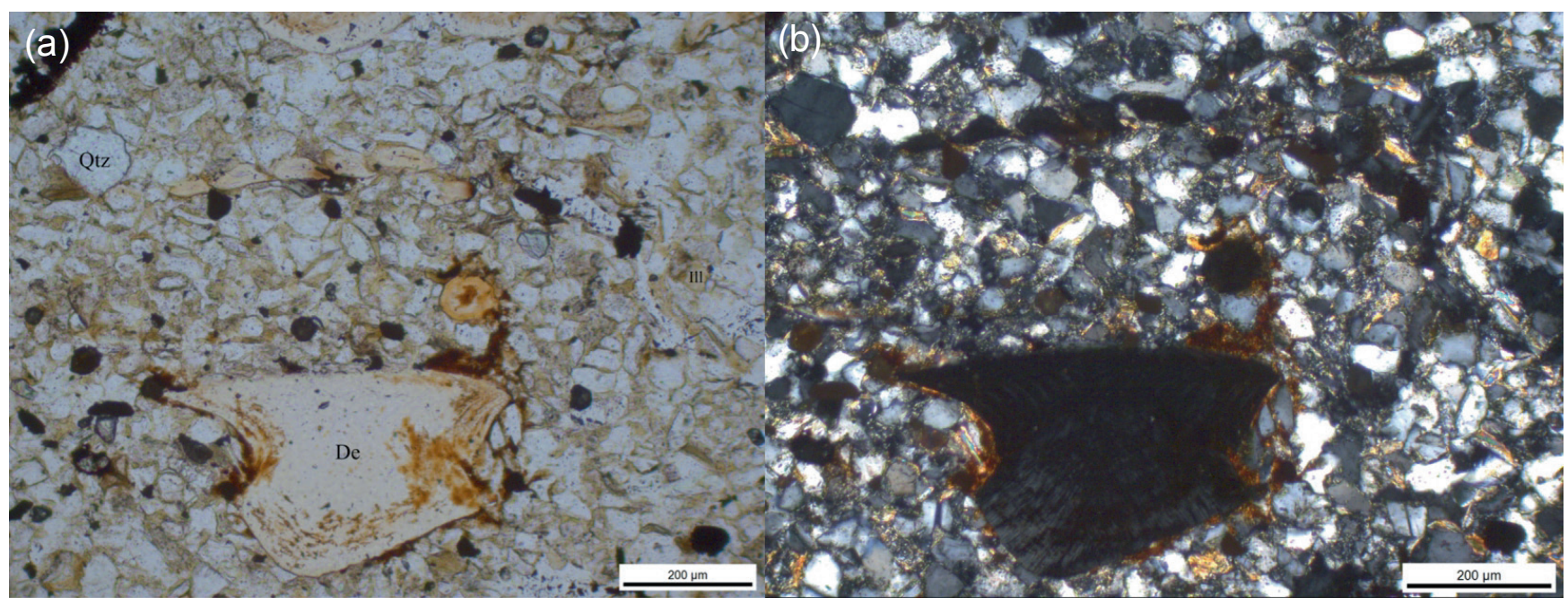

Fig. 1. Petrology of the Downton Bone Bed from a bone-rich horizon: (a) plane polarized light, quartz (Qtz), illite (Ill) and thelodont denticle (De); (b) cross-polarized light.

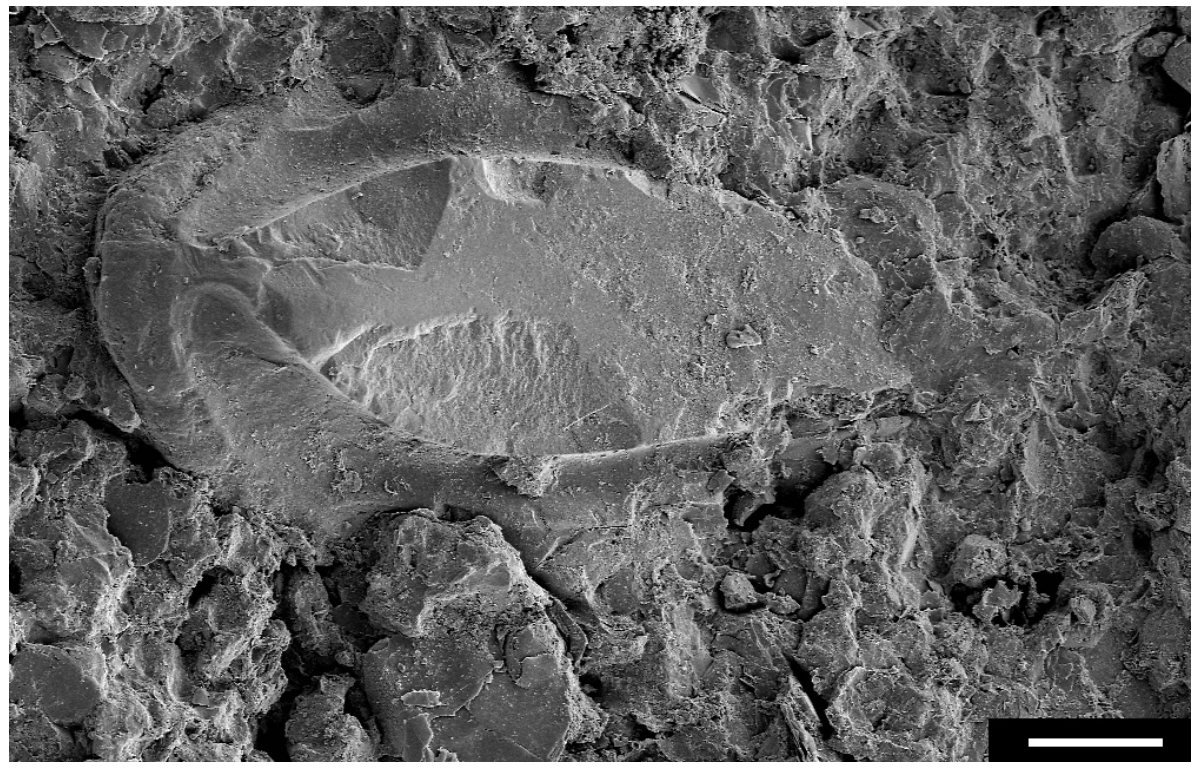

Fig. 2. Paralogania ludlowiensis (Gross, 1967) trunk scale in crown view, in situ on bedding surface. Scale bar $100 \mu \mathrm{m}$.

into four size fractions $(500,212,106$ and $75 \mu \mathrm{m})$ and then placed in sodium polytungstate (specific gravity 2.8 ) for heavy liquid separation using the method described by Savage (1988). The material recovered was of the same quality as that from the mechanical method (Fig. 3b). However, the quantity of fossil material recovered and the time the process took $(5 \mathrm{~min})$ shows that it is a far better technique than the mechanical method. A significant limiting factor for its use is cost (Table 1) so Selfrag is a non-viable option for processing numerous samples.

\section{Pre-treatment}

The same pre-treatment was conducted on all samples. The samples were washed with water mixed with $10 \mathrm{ml}$ Decon 90 to remove all modern organic material. A toothbrush was used to remove any material that did not initially wash off. After washing and cleaning, the samples were left to air dry.

\section{Health and safety}

It is very important when carrying out any scientific laboratory work to consider the health and safety aspects of any procedure. For the method used, the standard laboratory practice of wearing a lab coat, latex gloves and safety goggles is recommended. When using the microwave, further precautions should be taken. The microwave must be placed in a fume cupboard to allow any fumes from the paraffin to be drawn away and, while processing the sample, the hood should be drawn down to protect the user. It is also advisable after processing each sample to allow the Pyrex plate in the microwave to cool down to ensure that the equipment operates at a safe temperature.

\section{The paraffin expansion method}

To break down the Downton Bone Bed successfully the following method was used.

1. Cut the sample into blocks with a mass of $<100 \mathrm{~g}$. A rock splitter can be used to take advantage of the rock's natural weaknesses. This has two benefits: (1) it will fit into the ideal container (a $200 \mathrm{ml}$ Polytetrafluoroethylene (PTFE) beaker) and (2) the paraffin penetrates into smaller pieces more effectively because of their larger surface area to volume ratio.

2. Place the blocks in a large plastic bowl filled with liquid paraffin and allow to soak for $24 \mathrm{~h}$.

3. Remove the blocks from the paraffin and place on paper towels to remove excess liquid; the rock should appear damp rather than dripping wet. 


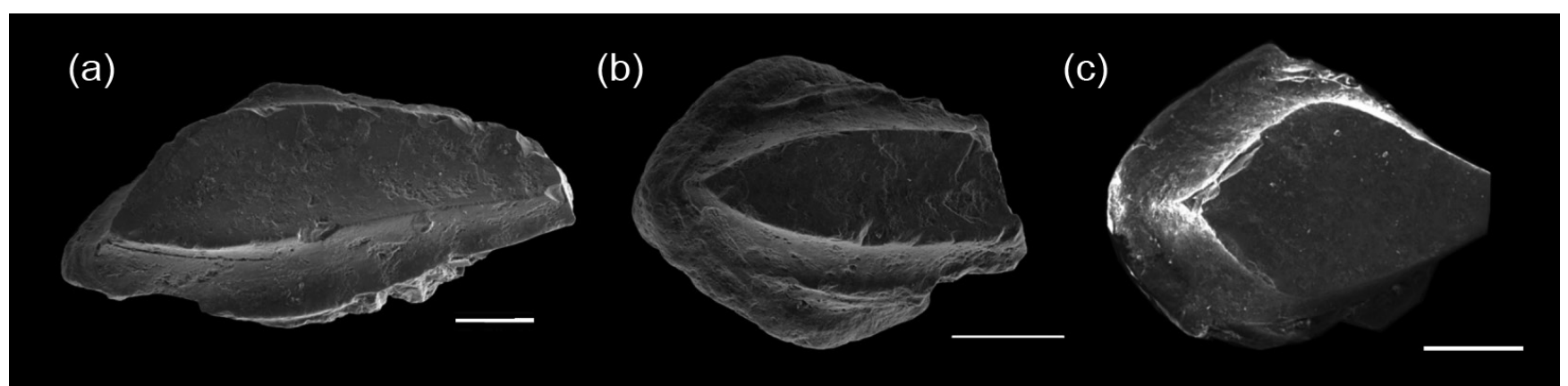

Fig. 3. Examples of the least damaged Paralogania ludlowiensis (Gross, 1967) trunk scales shown in crown view taken from each sample processed by the three different methods: (a) mechanical; (b) Selfrag; (c) paraffin expansion. Scale bar $200 \mu \mathrm{m}$.

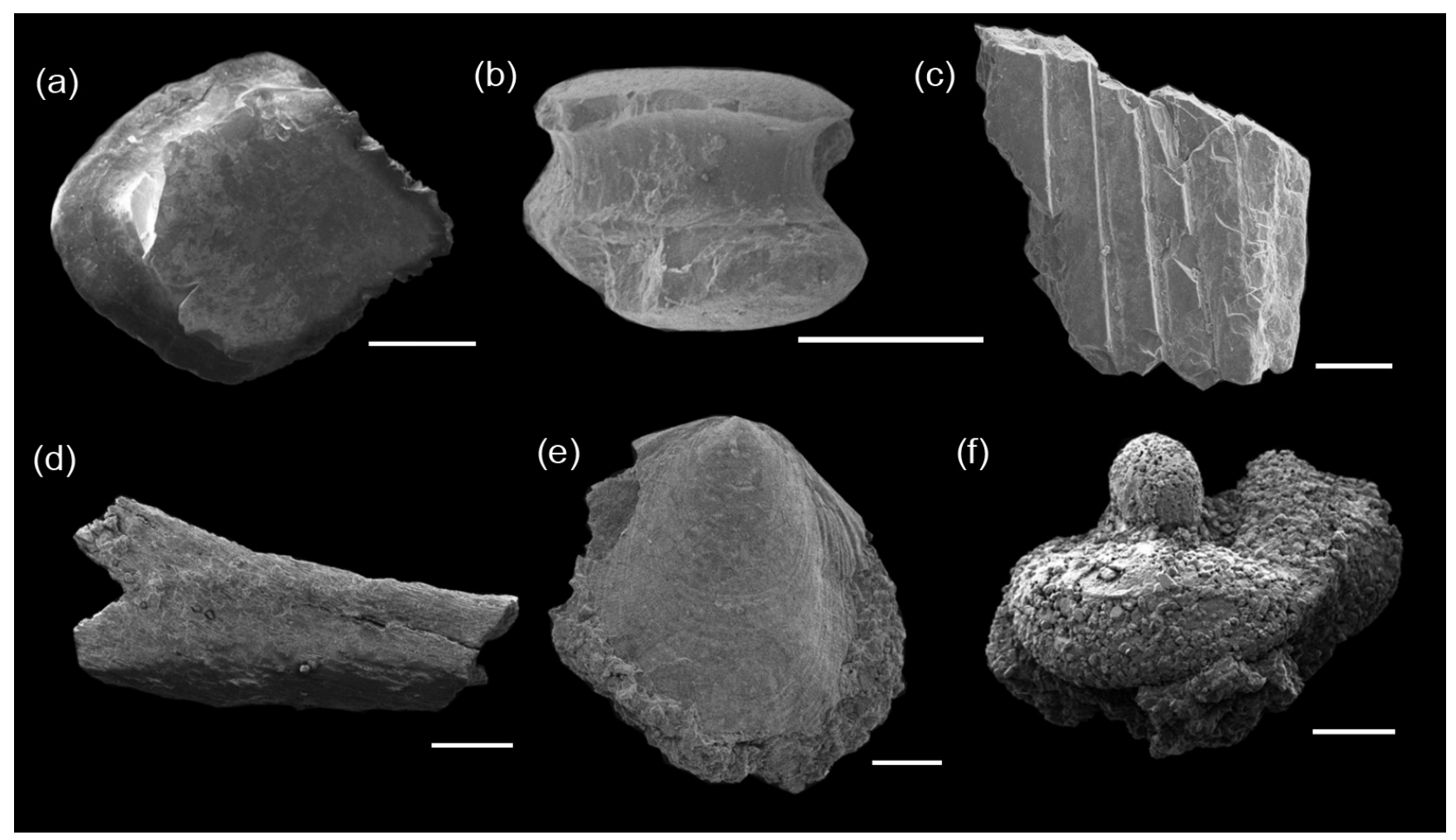

Fig. 4. Material produced using the paraffin expansion method showing preservation and the wide range of material released: (a) Paralogania ludlowiensis (Gross, 1967) trunk scale in crown view; (b) Thelodus parvidens (Agassiz, 1839) trunk scale in lateral view; (c) indeterminate acanthodian fragment in lateral view; (d) Hollandophyton colliculum (Rogerson et al., 2002); (e) lingulid brachiopod valve exterior; (f) internal mould of the ostracod Frostiella groenvalliana (Martinsson, 1963). Scale bars represent $300 \mu \mathrm{m}$.

Table 1. Comparison of the three methods used in this study

\begin{tabular}{lccc}
\hline & & Techniques \\
\cline { 2 - 3 } & Mechanical & Selfrag \\
\hline Time to process 1 kg of sample & 1 month & 5 minutes \\
Total amount of rock broken down (\%) & 40 & 100 & Poraffin expansion \\
Quality of fossil material extracted & Poor & 3 days & 60 \\
Cost to process per samples $(£)$ & 13 & Food & 14 \\
Types of fossils recovered & Fish, brachiopods & Fish, brachiopods & Fish, brachiopods, ostracods, plants \\
\hline
\end{tabular}

4. Place a block inside a $200 \mathrm{ml}$ PTFE beaker (chosen because they can withstand a high temperature).

5. Once the block has been placed inside the beaker, place a Pyrex watch glass on top to act as a lid to prevent fragments of rock from escaping from the beaker.

6. Place the beaker with watch glass into the microwave and turn on for $2 \mathrm{~min}$ at full power $(800 \mathrm{~W})$.
7. Carefully remove the beaker and pour its contents into a large bowl of cold water to quench the sediment and any remaining rock fragments.

8. After the processing is complete, pour the sediment through sieves of various sizes. For the purpose of this study, sieve sizes of $2.36 \mathrm{~mm}, 1.70 \mathrm{~mm}, 500 \mu \mathrm{m}, 212 \mu \mathrm{m}, 106 \mu \mathrm{m}$ and $75 \mu \mathrm{m}$ were used. 
9. Wash processed sample fractions in distilled water until clean and then place in an evaporating dish to air dry.

10. Once the sediment is dry, further separate the material using heavy liquids. Sodium polytungstate (SPT) with a specific gravity of 2.8 is commonly used to separate the phosphatic elements from the detrital grains (Savage 1988). However, it is also possible to pick the fossils directly from the residue.

A major advantage of this cheap and simple method is that a wide diversity of material can be recovered including not only vertebrates, but also invertebrates and plants (Figs 3c and 4).

\section{Discussion}

The method described herein represents a new combination of aspects of a number of previously used methods (Jones 1994; Green 2001). This paraffin expansion method for processing indurated bone beds described herein is similar to the petroleum spirit method described in Green (2001, p. 324). However, there are some key differences. The first is that the petroleum spirit method is recommended for less indurated rocks, such as shales (Green 2001). The petroleum spirit method also uses boiling water to break the rock down further, whereas the paraffin expansion method uses a microwave to achieve a much quicker result. The Downton Bone Bed has one major difference to other bone beds, which is the presence of organic-rich layers. This appears to be the key to the method's success. Paraffin is a solvent which subtly breaks down some of the organic matter within the bed creating more pore space. However, the process is not totally destructive to plant material as some has been recovered and does not appear damaged (Fig. 4d). The rapid heating of the paraffin to its boiling point of $280-350^{\circ} \mathrm{C}$ allows the build-up of volatiles and other gases within the pore spaces. This results in the sample being mechanically disintegrated by the gases in a process of vaporization, which is different from the petroleum spirit method which breaks the bonds within the clays, liberating the fossils from the rock. However, improvements can be made as not all of the sample was broken down (Table 1). To investigate why, these remaining indurated pieces of the samples were reprocessed. After a second cycle, the sample remained indurated. This was because the first round of processing had removed all the organic material; without this the paraffin has nothing to break down and in turn has no extra pore spaces to allow the gases to mechanically break the rock down. However, it is possible that the remaining aggregates could be subjected to other mechanical techniques having been weakened by the initial processing. Despite this, it is clear that the paraffin expansion method is the least destructive method to the fossils (Fig. 4; Table 1), which shows the range of taxa recovered. This includes complete brachiopods, which are usually broken when recovered using other methods. However brachiopods that were fragmented pre-deposition are also found in the paraffin expansion residue.

\section{Acknowledgements and Funding}

The author thanks C. Lyons of Downton Estates Ltd for permission to visit Weir Quarry, D. Loydell for editing and advice, A. Weh and Selfrag for running a test sample, E. Dyer and R. Hing for technical assistance and E. Hart for editing, support and discussion. Also thanked are the two referees, O. Green and C. G. Miller, for their helpful and constructive comments and advice. This paper is a contribution to the International Geoscience Programme (IGCP) Project 591 - The Early to Middle Palaeozoic Revolution.

\section{Scientific editing by Giles Miller}

\section{References}

Agassiz, L. 1839. Fishes of the Upper Ludlow rock. In: Murchison, R.I. (ed.) The Silurian System, Founded on Geological Researches. Richard \& John E. Taylor, London.

Antia, D.D.J. \& Whitaker, J.H.McD. 1978. A scanning electron microscope study of the genesis of the upper Silurian Ludlow Bone Bed. In: Whalley, W.B. (ed.) Scanning Electron Microscopy in the Study of Sediments. Geo Abstracts, Norwich, 119-136.

Bassett, M.G., Lawson, J.D. \& White, D.E. 1982. The Downton series as the fourth series of the Silurian system. Lethaia, 15, 1-24.

Eberth, D.A., Shannon, M. \& Noland, B.G. 2007. A bonebeds database: Classification, biases, and patterns of occurrence. In: Rogers, R.R., Eberth, D.A. \& Fiorillo, A.R. (eds) Bonebeds: Genesis, Analysis, and Paleobiological Significance. University of Chicago Press, Chicago, IL, USA, 132-219.

Giese, J., Seward, D., Gnos, E. \& Kurz, D. 2007. Comparative apatite fission track study of conventionally versus Selfrag Lab fragmented samples. Geochimica et Cosmochimica Acta, 71, A322.

Green, O.R. (ed.) 2001. A Manual of Practical Laboratory and Field Techniques in Palaeobiology. Springer, The Netherlands.

Gross, W. 1967. Über Thelodontier-Schuppen. Palaeontographica, A127, 1-67.

Jeppsson, L., Anehus, R. \& Fredholm, D. 1999. The optimal acetate buffered acetic acid technique for extracting phosphatic fossils. Journal of Paleontology, 73, 964-972.

Jones, R.A. 1994. The application of microwave technology to the oxidation of kerogen for use in palynology. Review of Palaeobotany and Palynology, 80, 333-338.

Loydell, D.K. \& Frýda, J. 2011. At what stratigraphical level is the mid Ludfordian (Ludlow, Silurian) positive carbon isotope excursion in the type Ludlow area, Shropshire, England? Bulletin of Geosciences, 86, 197-208.

Märss, T. \& Miller, C.G. 2004. Thelodonts and distribution of associated conodonts from the Llandovery-lowermost Lochkovian of the Welsh Borderland. Palaeontology, 47, 1211-1265.

Martinsson, A. 1963. The concealed Silurian of the Baltic area. Geologiska Föreningen i Stockholm Förhandlingar, 84, 539-545.

Miller, C.G. 1995. Ostracode and conodont distribution across the Ludlow/ Prídolí boundary of Wales and the Welsh Borderland. Palaeontology, 38, 341-384.

Miller, C.G. \& Märss, T. 1999. A conodont, thelodont and acanthodian fauna from the lower Prídolí (Silurian) of the Much Wenlock Area, Shropshire. Palaeontology, 42, 691-714.

Nestor, V. 2009. Biostratigraphy of the Ludlow chitinozoans from East Baltic drill cores. Estonian Journal of Earth Sciences, 58, 170-184.

Richardson, J.B. \& Rasul, S.M. 1990. Palynofacies in a Late Silurian regressive sequence in the Welsh Borderland and Wales. Journal of the Geological Society, London, 147, 675-686, http://doi.org/10.1144/gsigs.147.4.0675

Rixton, A.E. (ed.) 1976. Fossil Animals, Their Preparation and Conservation. Athlone Press, London, 59-83.

Rogerson, C., Edwards, D., Axe, L. \& Davies, K.L. 2002. A new embryophyte from the upper Silurian of Shropshire, England. Special Papers in Palaeontology, 67, 233-250.

Savage, N.M. 1988. The use of sodium polytungstate for conodont separations Journal of Micropalaeontology, 7, 39-40, http://doi.org/10.1144/jm.7.1.39

Swift, A. \& Martill, D.M. (eds). 1999. Fossils of the Rhaetian Penarth Group. Paleontological Association, London. 